\title{
Tuberculosis Treatment Adherence of Patients in Kosovo
}

\author{
Shaip Krasniqi, ${ }^{1}$ Arianit Jakupi, ${ }^{2}$ Armond Daci, ${ }^{3}$ Bahri Tigani, ${ }^{2}$ Nora Jupolli-Krasniqi, \\ Mimoza Pira, ${ }^{2}$ Valbona Zhjeqi, ${ }^{4}$ and Burim Neziri $^{5}$ \\ ${ }^{1}$ Institute of Pharmacology and Toxicology and Clinical Pharmacology, Faculty of Medicine, University of Prishtina "Hasan Prishtina", \\ Prishtina, Kosovo \\ ${ }^{2}$ Health Agency for Development (HAD), Prishtina, Kosovo \\ ${ }^{3}$ Department of Pharmacy, Faculty of Medicine, University of Prishtina "Hasan Prishtina", Prishtina, Kosovo \\ ${ }^{4}$ National Institute of Public Health of Kosovo, Prishtina, Kosovo \\ ${ }^{5}$ Institute of Clinical Physiology, Faculty of Medicine, University of Prishtina "Hasan Prishtina", Prishtina, Kosovo
}

Correspondence should be addressed to Burim Neziri; burim.neziri@uni-pr.edu

Received 29 June 2017; Revised 29 September 2017; Accepted 12 October 2017; Published 5 November 2017

Academic Editor: David C. Perlman

Copyright (c) 2017 Shaip Krasniqi et al. This is an open access article distributed under the Creative Commons Attribution License, which permits unrestricted use, distribution, and reproduction in any medium, provided the original work is properly cited.

Setting. The poor patient adherence in tuberculosis (TB) treatment is considered to be one of the most serious challenges which reflect the decrease of treatment success and emerging of the Multidrug Resistance-TB (MDR-TB). To our knowledge, the data about patients' adherence to anti-TB treatment in our country are missing. Objective. This study was aimed to investigate the antiTB treatment adherence rate and to identify factors related to eventual nonadherence among Kosovo TB patients. Design. This study was conducted during 12 months, and the survey was a descriptive study using the standardized questionnaires with total 324 patients. Results. The overall nonadherence for TB patient cohort was 14.5\%, 95\% CI (0.109-0.188). Age and place of residence are shown to have an effect on treatment adherence. Moreover, the knowledge of the treatment prognosis, daily dosage, side effects, and length of treatment also play a role. This was also reflected in knowledge regarding compliance with regular administration of TB drugs, satisfaction with the treatment, interruption of TB therapy, and the professional monitoring in the administration of TB drugs. Conclusion. The level of nonadherence TB treatment in Kosovar patients is not satisfying, and more health care worker's commitments need to be addressed for improvement.

\section{Introduction}

Tuberculosis (TB) remains still one of the most important socioeconomic global diseases with high infection and mortality rate [1]. The World Health Organization (WHO), in 2015, reported worldwide 10.4 million people infected with $\mathrm{TB}$ and annually 1.5 million patients' death $[2,3]$.

According to WHO reports, from a total number of infected people with TB, 123000 cases were diagnosed and reported as multidrug-resistant TB (MDR-TB). Nevertheless, the occurrence of MDR-TB is estimated to be almost four times higher, showing that detection and report of such cases are not in the expected level $[2,4]$.

The TB is considered as a global human threat and is included in United Nations (UN) millennium goals to reduce the risk from this disease [5]. According to these goals, there are still needs for more improvement, especially in the international coordinated plan to reduce the mortality rate, the incidence of MDR-RB patients, and risk from this disease overall [6].

Despite many achievements in the fight against TB, this disease is still challenging the human health [7].

The global initiatives to fight TB are determined by WHO strategy, directly observed therapy short course (DOTS), and one of the most important components of this strategy is the effective TB drug supply and management system. One of the important issues that guarantee the success of the treatment is the degree of anti-TB drug patient's compliance or adherence. The poor patient adherence is considered to be one of the most serious challenges which reflects the decrease of treatment success and emerging of the MDR-TB [8-10]. Directly observed therapy (DOT) was outlined to support 
TB treatment adherence and completion, of course, resulting in reduced morbidity and mortality and restraining TB drug resistance.

Although the implementation of DOTS strategy improved the treatment success of TB patients, there is evidence showing that direct observation is not implemented systematically and level of patient's adherence to TB treatment is not satisfying (from $4=50 \%$ in India, $88.5 \%$ in Ethiopia, and $88.8 \%$ in China) [11-13].

Kosovo, the state in Southeastern Europe, has a relatively high number of TB cases in this region [14]. Until 2000, the ratio of the rural versus urban general population in Kosovo was $62 \%$ versus $38 \%$ [15], while after this period massive migration happened from rural regions. The Global Fund to Fight AIDS, Tuberculosis, and Malaria supported Kosovo with grants which resulted in substantial reduction in a number of TB cases (from 85.9/100,000 in 2000 to 46/100,000 inhabitants in 2012) [16].

Even with this improvement, Kosovo remains among states with highest notification rates of $\mathrm{TB}$ in the region and more attention is needed. To our knowledge, the data about patients' adherence to anti-TB treatment in our country are missing; therefore, this study was aimed to investigate the anti-TB treatment adherence rate and to identify factors related to eventual nonadherence among Kosovo TB patients.

\section{Material and Methods}

2.1. Setting and Design. It was a descriptive study conducted for 12 months using standardized questionnaires. The interview was conducted for $324 \mathrm{~TB}$ patients.

2.2. Sample Size. According to data of the National Tuberculosis Control Program in Kosovo, in 2012, 968 new and recurrent/relapsed TB patients were registered. From this total number of active TB patients in this year, we have interviewed 350 patients in the survey. A total number of 324 were completely responsive, while 26 patients answered partially which we have excluded from data analysis. TB patients were recruited by using a systematic sampling method after fulfillment of inclusion criteria such as a registered TB patients with confirmed diagnosis of TB and being regularly supplied with TB drugs.

The nonadherence was classified as follows: patients who did not take the TB drugs for more than three days were considered nonadherent to TB drugs.

Data were obtained from TB out-patient registers from TB dispensaries in six administrative regions of Kosovo. The TB health centers are mainly located in the distance less than $10 \mathrm{~km}$ for each region, ensuring easy access for patients to these TB centers.

The random methodology was used to recruit study participants to assess the level of adherence to anti-TB treatment. We have recruited each third patient found in TB out-patient register. A sample size of 324 reached the target to estimate the level of TB drug adherence for $90 \%$ level of adherence with a 5\% margin of error and 95\% confidence.

The main indicator to allocate the TB patient adherent or nonadherent was the fact if the patient has forgotten to receive the TB drugs in a period longer than three days.
The patients who were not mentally capable of answering due to accompanied mentally diseases during the interview were excluded from the study. From 350 interviewed patients, 26 patients were excluded due to incorrect answers.

The cohort of TB patients was monthly supervised by the pulmonary doctor. Indeed, in a monthly basis, the TB patients visit the TB dispensary for TB drug supply and undergo the medical evaluation by the pulmonary doctor.

2.3. Management of Data. The collection of the data has been performed using the standardized questionnaires, which initially were standardized to yield the reliable results of TB treatment adherence.

In this study, we have enrolled the responders from all medical centers that provide health care for TB patients in Kosovo's health system which has ensured the distributed representation of TB patients from all regions. Initially, during the visits, the research team stayed at these centers during working hours, and they accessed the documentation of all the patients that received anti-TB therapy and start to trace these patients to perform the individual interviews. Patients' knowledge about TB treatment adherence was ascertained based on their responses obtained during a face-to-face interview.

The questionnaire was composed of five chapters: (a) sociodemographic; (b) level of knowledge on tuberculosis disease; (c) knowledge on tuberculosis treatment; (d) TB treatment adherence characteristics, and (e) health system and other features.

2.4. Statistical Analysis. We used a descriptive and comparative statistics. The differences between groups and the proportion of poor adherence for all variables were analyzed using chi-square $\chi 2$ test and minimum significant level of $p<0.05$. All statistical analysis was performed using the Graph Prism 6.0 (Software).

2.5. Ethical Issue. The study protocol was approved by Country Coordinating Mechanisms (CCM) established by the Ministry of Health of Kosovo. Initially, we present the aim of this survey and other relevant information to TB patients. The verbal consent was obtained, taking into consideration the fact that we have expected a relative number of patients with low-level literacy, with elementary school education (37.04\%), and who are not literate (14.81\%), which might influence their ability to understand and to sign the document. Data collected by interview were managed anonymously using the codes and no names.

\section{Results}

A total of 350 TB patients were interviewed, while only 324 completed the interview (response rate of 92.6\%). About half of TB patients $(49.38 \%)$ enrolled in the study were male while other patients were female $(50.4 \%)$. Based on age, the patients included in survey have been divided into seven groups as follows: in age group 0-15 years $(4.01 \%)$, followed by a group of 16-25 (29.01\%), 26-35 (12.35\%), 36-45 (11.73), 46-55 (11.73\%), 56-65 (12.04), and >65 years old (19.14). 
TABLE 1: Sociodemographic data http://www.sample-size.net/confidence-interval-proportion/.

\begin{tabular}{|c|c|c|c|c|c|c|c|}
\hline \multirow[t]{2}{*}{ Variables } & \multicolumn{2}{|c|}{ Total $(n=324)$} & \multicolumn{2}{|c|}{$\begin{array}{l}\text { Adherent }(n=277) \\
95 \% \text { CI }(0.812-0.892)\end{array}$} & \multicolumn{2}{|c|}{$\begin{array}{l}\text { Nonadherent }(n=47) \\
95 \% \text { CI }(0.109-0.188)\end{array}$} & \multirow[t]{2}{*}{$p$ value } \\
\hline & $N$ & $\%$ & $n$ & $\%$ & $n$ & $\%$ & \\
\hline \multicolumn{8}{|l|}{ Sex } \\
\hline Male & 160 & $49.38 \%$ & 134 & $48.38 \%$ & 26 & $55.32 \%$ & \multirow{2}{*}{0.326} \\
\hline Female & 164 & $50.62 \%$ & 143 & $51.62 \%$ & 21 & $44.68 \%$ & \\
\hline \multicolumn{8}{|l|}{ Age (years old) } \\
\hline $0-15$ & 13 & $4.01 \%$ & 13 & $4.69 \%$ & 0 & $0 \%$ & \multirow{7}{*}{$0.018^{*}$} \\
\hline $16-25$ & 94 & $29.01 \%$ & 82 & $29.60 \%$ & 12 & $25.53 \%$ & \\
\hline $26-35$ & 40 & $12.35 \%$ & 38 & $13.72 \%$ & 2 & $4.26 \%$ & \\
\hline $36-45$ & 38 & $11.73 \%$ & 29 & $10.47 \%$ & 9 & $19.15 \%$ & \\
\hline $46-55$ & 38 & $11.73 \%$ & 30 & $10.83 \%$ & 8 & $17.02 \%$ & \\
\hline $56-65$ & 39 & $12.04 \%$ & 31 & $11.19 \%$ & 8 & $17.02 \%$ & \\
\hline$>65$ & 62 & $19.14 \%$ & 54 & $19.50 \%$ & 8 & $17.02 \%$ & \\
\hline \multicolumn{8}{|l|}{ Place of residence } \\
\hline Urban & 125 & $38.58 \%$ & 100 & $36.10 \%$ & 25 & $53.19 \%$ & \multirow{2}{*}{$0.015^{*}$} \\
\hline Rural & 199 & $61.42 \%$ & 177 & $63.90 \%$ & 22 & $46.81 \%$ & \\
\hline \multicolumn{8}{|l|}{ Marital status } \\
\hline Married & 127 & $39.20 \%$ & 107 & $38.63 \%$ & 20 & $42.55 \%$ & \multirow{4}{*}{0.561} \\
\hline Not married & 194 & $59.88 \%$ & 168 & $60.65 \%$ & 26 & $55.32 \%$ & \\
\hline Divorced & 2 & $0.62 \%$ & 1 & $0.36 \%$ & 1 & $2.13 \%$ & \\
\hline Widow & 1 & $0.31 \%$ & 1 & $0.36 \%$ & 0 & $0.00 \%$ & \\
\hline \multicolumn{8}{|l|}{ Education } \\
\hline No education & 48 & $14.81 \%$ & 38 & $13.72 \%$ & 10 & $21.28 \%$ & \multirow{4}{*}{0.568} \\
\hline Elementary school & 120 & $37.04 \%$ & 104 & $37.55 \%$ & 16 & $34.04 \%$ & \\
\hline High school & 124 & $38.27 \%$ & 107 & $38.63 \%$ & 17 & $36.17 \%$ & \\
\hline University & 32 & $9.88 \%$ & 28 & $10.10 \%$ & 4 & $8.51 \%$ & \\
\hline \multicolumn{8}{|l|}{ Employment } \\
\hline Not employed & 209 & $64.51 \%$ & 179 & $64.62 \%$ & 30 & $63.83 \%$ & \multirow{3}{*}{0.670} \\
\hline Employed & 57 & $17.59 \%$ & 47 & $16.97 \%$ & 10 & $21.28 \%$ & \\
\hline Student/pupil & 58 & $17.90 \%$ & 51 & $18.41 \%$ & 7 & $14.89 \%$ & \\
\hline
\end{tabular}

${ }^{*} p<0.05$.

Most TB patients were not married (59.88\%) and had elementary (37.04\%) and high school education $(38.27 \%)$ with higher unemployed rates (64.51\%) (Table 1).

Moreover, the knowledge of patients about TB disease showing the level of health education about TB was shown in Table 2. According to DOTS, all these patients had undergone the health education module for TB disease. Mostly respondents do not know or had a wrong answer regarding what causes $\mathrm{TB}$ (56.18\% and $22.22 \%$, resp.). We get the similar structure of answers in questions how TB is spread and how TB is prevented where the cohort of patients with answers do not know or not true were higher compared to patients with the exact answer $(62.65 \%$ and 72.22 versus $37.35 \%$ and $27.78 \%$, resp.), while the majority of TB patients had a correct answer compared to those with an incorrect answer to question is TB cured ( $88.27 \%$ versus $11.73 \%)$.

However, the knowledge about TB therapy is represented in Table 3. Following this issue, the highest structure of respondents answered correctly for the length of TB treatment and about colors of TB drugs (75.31\% and $65.43 \%)$. In majority cases, they answered not correctly about names of TB drugs, the daily dosage of TB drugs, and knowledge about the side effect of TB drugs (86.73\%, 72.22\%, and 76.85\%).

The comprehensive data about knowledge for TB drug compliance and risk behavior of TB patients were shown in Table 4. These results highlighted different variables reflecting the optimal knowledge about TB treatment compliance of TB patients registered in our study.

Almost $81.17 \%$ of patient answered correctly for the importance of regular administration of TB drugs, $73.15 \%$ reported a regular supply of free TB drugs, $95.3 \%$ of those were satisfied with treatment in the health center, and $68.52 \%$ of patients have a health center in a distance less than $10 \mathrm{~km}$. We had only $1.85 \%$ of patients drinking alcohol, while $11.42 \%$ were smokers. The unfavorable finding was the structure of patients with interruption of TB therapy after three months, 
TABLE 2: Knowledge for TB disease.

\begin{tabular}{|c|c|c|c|c|c|c|c|}
\hline \multirow[t]{2}{*}{ Variables } & \multicolumn{2}{|c|}{ Total $(n=324)$} & \multicolumn{2}{|c|}{$\begin{array}{l}\text { Adherent }(n=277) \\
95 \% \text { CI }(0.812-0.892)\end{array}$} & \multicolumn{2}{|c|}{$\begin{array}{c}\text { Nonadherent }(n=47) \\
95 \% \text { CI }(0.109-0.188)\end{array}$} & \multirow[t]{2}{*}{$p$ value } \\
\hline & $N$ & $\%$ & $N$ & $\%$ & $n$ & $\%$ & \\
\hline \multicolumn{8}{|l|}{ What causes TB } \\
\hline Not true & 72 & $22.22 \%$ & 64 & $23.10 \%$ & 8 & $17.02 \%$ & \multirow{3}{*}{0.407} \\
\hline True & 70 & $21.60 \%$ & 61 & $22.03 \%$ & 9 & $19.15 \%$ & \\
\hline Do not know & 182 & $56.18 \%$ & 152 & $54.87 \%$ & 30 & $63.83 \%$ & \\
\hline \multicolumn{8}{|l|}{ How TB is spread } \\
\hline Not true & 79 & $24.38 \%$ & 67 & $24.19 \%$ & 12 & $25.53 \%$ & \multirow{3}{*}{0.207} \\
\hline True & 121 & $37.35 \%$ & 108 & $38.99 \%$ & 13 & $27.66 \%$ & \\
\hline Do not know & 124 & $38.27 \%$ & 102 & $36.82 \%$ & 22 & $46.81 \%$ & \\
\hline \multicolumn{8}{|c|}{ How it is prevented } \\
\hline Not true & 72 & $22.22 \%$ & 62 & $22.38 \%$ & 10 & $21.28 \%$ & \multirow{3}{*}{0.864} \\
\hline True & 90 & $27.78 \%$ & 78 & $28.16 \%$ & 12 & $25.53 \%$ & \\
\hline Do not know & 162 & $50.00 \%$ & 137 & $49.46 \%$ & 25 & $53.19 \%$ & \\
\hline \multicolumn{8}{|l|}{ Is TB cured } \\
\hline Not true & 9 & $2.78 \%$ & 5 & $1.81 \%$ & 4 & $8.51 \%$ & \multirow{3}{*}{$0.003^{* *}$} \\
\hline True & 286 & $88.27 \%$ & 252 & $90.97 \%$ & 34 & $72.34 \%$ & \\
\hline Do not know & 29 & $8.95 \%$ & 20 & $7.22 \%$ & 9 & $19.15 \%$ & \\
\hline
\end{tabular}

TABLE 3: Knowledge for TB drugs.

\begin{tabular}{|c|c|c|c|c|c|c|c|}
\hline \multirow[t]{2}{*}{ Variables } & \multicolumn{2}{|c|}{ Total $(n=324)$} & \multicolumn{2}{|c|}{$\begin{array}{c}\text { Adherent }(n=277) \\
95 \% \text { CI }(0.812-0.892)\end{array}$} & \multicolumn{2}{|c|}{$\begin{array}{c}\text { Nonadherent }(n=47) \\
95 \% \text { CI }(0.109-0.188)\end{array}$} & \multirow[t]{2}{*}{$p$ value } \\
\hline & $N$ & $\%$ & $n$ & $\%$ & $n$ & $\%$ & \\
\hline \multicolumn{8}{|c|}{ Knowledge about the names of TB drugs } \\
\hline Not true & 22 & $6.79 \%$ & 16 & $5.78 \%$ & 6 & $12.77 \%$ & \multirow{3}{*}{0.233} \\
\hline True & 43 & $13.27 \%$ & 37 & $13.36 \%$ & 6 & $12.77 \%$ & \\
\hline Do not know & 259 & $79.94 \%$ & 224 & $80.86 \%$ & 35 & $74.46 \%$ & \\
\hline \multicolumn{8}{|c|}{$\begin{array}{l}\text { Knowledge about the length of treatment } \\
\text { of TB drugs }\end{array}$} \\
\hline Not true & 19 & $5.86 \%$ & 15 & $5.42 \%$ & 4 & $8.52 \%$ & \multirow{3}{*}{$0.018^{*}$} \\
\hline True & 244 & $75.31 \%$ & 216 & $77.98 \%$ & 28 & $59.57 \%$ & \\
\hline Do not know & 61 & $18.83 \%$ & 46 & $16.60 \%$ & 15 & $31.91 \%$ & \\
\hline \multicolumn{8}{|c|}{$\begin{array}{l}\text { Knowledge about the daily dosages of TB } \\
\text { drugs }\end{array}$} \\
\hline Not true & 16 & $4.94 \%$ & 7 & $2.53 \%$ & 9 & $19.15 \%$ & \multirow{3}{*}{$0.0001^{* *}$} \\
\hline True & 90 & $27.78 \%$ & 79 & $28.52 \%$ & 11 & $23.40 \%$ & \\
\hline Do not know & 218 & $67.28 \%$ & 191 & $68.95 \%$ & 27 & $57.45 \%$ & \\
\hline \multicolumn{8}{|c|}{ Knowledge about the colors of TB drugs } \\
\hline Not true & 112 & $34.57 \%$ & 93 & $33.57 \%$ & 19 & $40.44 \%$ & \multirow{2}{*}{0.261} \\
\hline True & 212 & $65.43 \%$ & 184 & $66.43 \%$ & 28 & $57.46 \%$ & \\
\hline \multicolumn{8}{|c|}{ Knowledge about side effects of TB drugs } \\
\hline Not true & 249 & $76.85 \%$ & 207 & $74.73 \%$ & 42 & $89.36 \%$ & \multirow{2}{*}{$0.007^{* *}$} \\
\hline True & 75 & $23.15 \%$ & 70 & $25.27 \%$ & 5 & $10.64 \%$ & \\
\hline
\end{tabular}

${ }^{*} p<0.05 ;{ }^{* *} p<0.001 ;{ }^{* * *} p<0.0001$. 
TABLE 4: Knowledge of TB drug compliance and risk behavior of TB patients.

\begin{tabular}{|c|c|c|c|c|c|c|c|}
\hline \multirow[t]{2}{*}{ Variables } & \multicolumn{2}{|c|}{ Total $(n=324)$} & \multicolumn{2}{|c|}{$\begin{array}{l}\text { Adherent }(n=277) \\
95 \% \text { CI }(0.812-0.892)\end{array}$} & \multicolumn{2}{|c|}{$\begin{array}{l}\text { Nonadherent }(n=47) \\
95 \% \text { CI }(0.109-0.188)\end{array}$} & \multirow[t]{2}{*}{$p$ value } \\
\hline & $N$ & $\%$ & $N$ & $\%$ & $n$ & $\%$ & \\
\hline \multicolumn{8}{|c|}{$\begin{array}{l}\text { Importance of regular administration of } \\
\text { TB drugs }\end{array}$} \\
\hline Not true & 61 & $18.83 \%$ & 44 & $15.88 \%$ & 17 & $36.17 \%$ & \multirow{2}{*}{$0.001^{* *}$} \\
\hline True & 263 & $81.17 \%$ & 233 & $84.12 \%$ & 30 & $63.83 \%$ & \\
\hline \multicolumn{8}{|c|}{$\begin{array}{l}\text { Administration of TB drugs in a presence } \\
\text { of a nurse or family member }\end{array}$} \\
\hline No & 202 & $62.35 \%$ & 166 & $59.93 \%$ & 36 & $76.60 \%$ & \multirow{2}{*}{$0.039^{*}$} \\
\hline Yes & 122 & $37.65 \%$ & 111 & $40.07 \%$ & 11 & $27.66 \%$ & \\
\hline \multicolumn{8}{|c|}{ Regular supply of TB drugs } \\
\hline No & 87 & $26.85 \%$ & 77 & $27.80 \%$ & 10 & $21.28 \%$ & \multirow{2}{*}{0.351} \\
\hline Yes & 237 & $73.15 \%$ & 200 & $72.20 \%$ & 37 & $78.72 \%$ & \\
\hline \multicolumn{8}{|c|}{$\begin{array}{l}\text { Satisfied with the treatment in the health } \\
\text { center }\end{array}$} \\
\hline No & 15 & $4.63 \%$ & 6 & $2.17 \%$ & 9 & $19.15 \%$ & \multirow{2}{*}{$0.0001^{* * *}$} \\
\hline Yes & 309 & $95.37 \%$ & 271 & $97.83 \%$ & 38 & $80.85 \%$ & \\
\hline \multicolumn{8}{|l|}{ BCG vaccine } \\
\hline No & 29 & $8.95 \%$ & 23 & $8.30 \%$ & 6 & $12.77 \%$ & \multirow{3}{*}{0.085} \\
\hline Yes & 150 & $46.30 \%$ & 124 & $44.77 \%$ & 26 & $55.32 \%$ & \\
\hline Do not know & 145 & $44.75 \%$ & 130 & $46.93 \%$ & 15 & $31.91 \%$ & \\
\hline \multicolumn{8}{|c|}{ Interruption of TB therapy after 3 months } \\
\hline No & 277 & $85.49 \%$ & 250 & $90.25 \%$ & 27 & $57.45 \%$ & \multirow{2}{*}{$0.0001^{* *}$} \\
\hline Yes & 47 & $14.51 \%$ & 27 & $9.75 \%$ & 20 & $42.55 \%$ & \\
\hline \multicolumn{8}{|c|}{ Distance from the health center } \\
\hline$\geq 10 \mathrm{~km}$ & 102 & $31.48 \%$ & 88 & $31.77 \%$ & 14 & $29.79 \%$ & \multirow{2}{*}{0.761} \\
\hline$\leq 10 \mathrm{~km}$ & 222 & $68.52 \%$ & 189 & $68.23 \%$ & 33 & $70.21 \%$ & \\
\hline \multicolumn{8}{|l|}{ Smoking } \\
\hline Yes & 37 & $11.42 \%$ & 30 & $10.83 \%$ & 7 & $14.89 \%$ & \multirow{2}{*}{0.391} \\
\hline No & 287 & $88.58 \%$ & 247 & $89.17 \%$ & 40 & $85.11 \%$ & \\
\hline \multicolumn{8}{|l|}{ Alcohol } \\
\hline Yes & 6 & $1.85 \%$ & 4 & $1.44 \%$ & 2 & $4.26 \%$ & \multirow{2}{*}{0.231} \\
\hline No & 318 & $98.15 \%$ & 273 & $98.56 \%$ & 45 & $95.74 \%$ & \\
\hline
\end{tabular}

${ }^{*} p<0.05 ;{ }^{* *} p<0.001 ;{ }^{* * *} p<0.0001$.

due to a nonregular intake of drugs by them because of not respecting the pulmonary doctor's advice (14.5\%).

The overall adherence and nonadherence for TB patient cohort included in the survey were $85.5 \%$ (95\% CI $0.812-0.892$ ) and $14.5 \%$ (95\% CI $0.109-0.188)$, respectively.

The major factors such as the knowledge about the daily dosage of TB drug were shown to be a difference between adherent and nonadherent group $(p<0.0001)$. Also, the knowledge about the length of TB treatment and side effect of TB drugs is significantly different between adherent and nonadherent group ( $p<0.018$ and $p<0.007$, resp.). Our results show that the other variables in this context had no effects on TB treatment adherence (Table 3 ).

The most important variables with the highest level of significance in TB treatment adherence were the regular administration of TB drugs $(p<0.001)$, satisfaction with the treatment in the health center $(p<0.001)$, and interruption of TB therapy after three months $(p<0.001)$.

Also, the presence of a nurse or family member in the administration of TB drugs was considered to be different between the compared groups $(p<0.039)$ (Table 4$)$. Other variables presented in Table 4 had no substantial significance in TB treatment adherence in patients involved in our study.

However, minor influencing factors for nonadherence to anti-TB treatment such as variables of knowledge about TB disease did not show a significant effect on the TB treatment adherence, while the impact of knowledge about the question regarding the $\mathrm{TB}$ treatment had a significant impact on TB treatment adherence $(p<0.001)$ (Table 2). Moreover, there was a significant difference between the adherent and 
nonadherent group's age $(p<0.018)$ with an increased nonadherence level in ages from 36 to 65 years old compared to adherence levels as well as place of residence with an increased nonadherence level in urban compared to the rural place of residence $(p<0.015)$, while other variables such as sex, marital status, education, and employment did not affect TB treatment adherence (Table 1).

\section{Discussion}

Besides intensive implementation of TB-DOTS control strategy, the treatment adherence for tuberculosis infection remains suboptimal in the majority of countries with a moderate and high prevalence of TB disease [3].

The treatment compliance with antituberculosis drugs is an essential part of DOTS and is mandatory for achieving the TB treatments' success [17].

Nonadherence to anti-TB treatment might trigger TB drug resistance which prolongs the infectiousness of disease and increases the relapse and death of patients [18].

The official registered number of TB patients in Kosovo during 2012 was 968 [14]. Our study results indicate that, from 324 interviewed TB patients, $85.5 \%$ adhered to the TB treatment regimen. This TB treatment adherence is lower than what was reported in Tanzania (95\%) [19] and similar with results reported in Uganda (92\%) [20]. The treatment adherence in our study was better to compare to adherence reported from several studies conducted in different countries with high prevalence of TB disease, such as in Iran (70\%) [21], Ethiopia (79\%) [22], and India (59.5\%) [23].

Data from the literature present that the incidence of tuberculosis is usually higher in males than female TB patients. In our study, the genders are almost equally represented among cohort of patients with no impact on TB treatment adherence. Similar results about gender distribution found in TB patients are also reported in other related studies $[24,25]$.

The ratio of $\mathrm{TB}$ population in urban and rural areas is approximately 1.1 to 0.9 and has a significant effect on TB patient adherence, while in a research report published in Holland the ratio of the TB patients in urban and rural areas was 3.8 to 1 [26]. A dominance of TB patients in urban areas is also reported in other countries in Europe [27]. Taking into consideration that, in our country, in the last two decades there was a massive migration of population from rural towards urban locations, this phenomenon reflected in the ratio of TB patients between urban and rural regions $(61.42 \%$ versus $38.58 \%$ ) was registered in our survey.

Furthermore, urban location was shown to have a similar number of adherents comparing to total urban versus rural patients and a higher number of nonadherent patients compared to rural location.

The majority of the patients were from 16 to 25 years old and not married. This group of patients usually is young people living a sedentary life alone without family care. The minor influencing factors including age group show a significant difference in TB treatment adherence while marital status had no impact.
We also found that education level and employment do not play a role in TB treatment adherence. Nevertheless, the educational attainment usually is correlated with patient's TB knowledge and seems to have an impact on TB treatment adherence, while the employment does not have an effect $[22,28]$.

There are also reports that educational level, type or residence, manufacturing industries, and service sectors were associated with poor adherence in the developed countries [29]. In general, we have shown that from the sociodemographic variables in our study only age group and location influenced the level of TB treatment adherence.

We found that a high number of TB patients answered not properly about causes of TB disease, its contagious rate, and TB prevention, reflecting the lack of basic knowledge about the disease. All these variables were without impact between adherent and nonadherent patients, while the knowledge about whether TB is cured was significant between these two groups of patients. Similar results found other researchers presenting inadequate level of TB knowledge in patients in Equatorial Guinea [28] and Ethiopia [30].

Moreover, our results regarding major influencing factors including knowledge about TB treatments including daily dosages, the length of treatment, and side effects have shown to play a role in treatment adherence. The level of knowledge for TB treatment in our study is not sufficient and can be due to non-well-established communication between health staff and patients and due to incorrect perception and misunderstanding of information received from health care professionals of TB patients about treatment. These findings are in line also with other studies which also recommend more attention to improve the communication with TB patients [31,32].

The analyses of knowledge for TB compliance yielded the lack of knowledge between adherent and nonadherent patients in several important and variables such as importance of regular administration of TB drugs, satisfaction with treatment in the health centers, interruption of therapy after three months, and administration of TB therapy in the monitoring of nurse or family members. These variables represent a core of direct indicators and major influencing factors for $\mathrm{TB}$ adherence and its consensus that they are the most useful set of indicators for evaluation of TB treatment adherence [33]. Other variables, such as a regular supply of TB drugs, BCG vaccine, distance from health care center, alcohol use, and smoking which are frequently found in the literature to be associated with a higher risk of TB treatment default, did not reflect the increased risk for TB treatment nonadherence.

The supply of TB drugs in Kosovo is supported by Global Fund, and no interruption in drug delivery was registered until know, while the alcohol use and smoking habits were relatively small in our TB study patients.

Our results suggest that TB patient's adherence is multifactorial and cross-variate dynamic phenomenon which is influenced by several groups of medical, sociocultural, and behavioral factors [34].

To achieve more objective results on the patient's compliance with anti-TB drugs, other studies should be conducted in analyzing factors such as the TB patients' stigma, the patients 
and their family members, and the evaluation of patient's perception about treatment adherence.

The limitations of our study were that we did not include TB patients in the active phase of TB disease which were under direct supervision of medical staff. Moreover, the data are obtained from direct contact with $\mathrm{TB}$ patients and did not include the family members and medical staff who are responsible for monitoring and facilitating the TB treatment adherence. Finally, the data were analyzed by descriptive statistics and not by multivariate analysis, and we consider that as a statistical limitation.

Overall, we conclude that level of nonadherence in Kosovo patients was not satisfying and more health care worker's actions need to be addressed for improvement. The improvement of TB treatment adherence should be focused to increase the knowledge of $\mathrm{TB}$ disease and treatment performing more effective health education, to increase the satisfactory level of patients with health medical services, and establishing a regular monitoring system through descriptive studies to identify patients with high risk for nonadherence of TB drugs (patients living alone and other not motivated patients). Intensive health education program for TB patients and their family member should be focused to motivate the TB treatment adherence and regular visits to health facilities and to provide more information about the benefit and safety profile of TB drugs.

For additional measures we consider the organization of the modality for peer assistance TB patients working group, establishing different social communications networks to facilitate the TB treatment adherence.

Finally, we recommend more comprehensive incentives program to improve the allure of TB patients for visiting the treatment center.

\section{Conflicts of Interest}

The authors have no conflicts of interest that are directly relevant to the content of this article.

\section{Authors' Contributions}

Shaip Krasniqi and Arianit Jakupi equally contributed to this work.

\section{Acknowledgments}

This survey was financially supported by the Global Fund to Fight AIDS, Tuberculosis, and Malaria, within the Project for Kosovo "Maintaining and Scaling Up Tuberculosis Prevention and Treatment Activities in Kosovo" (Reference no. KOS-911-G05-T).

\section{References}

[1] WHO, "Global tuberculosis report WHO Library Cataloguingin-Publication Data," p. 204, 2015.

[2] WHO, "Global tuberculosis report," 2015.
[3] E. Oren, M. L. Bell, F. Garcia, C. Perez-Velez, and L. B. Gerald, "Promoting adherence to treatment for latent TB infection through mobile phone text messaging: study protocol for a pilot randomized controlled trial," Pilot and Feasibility Studies, vol. 3, no. 1, 2017.

[4] E. A. Kendall, A. S. Azman, F. G. Cobelens, and D. W. Dowdy, "MDR-TB treatment as prevention: the projected populationlevel impact of expanded treatment for multidrug-resistant tuberculosis," PLoS ONE, vol. 12, no. 3, Article ID e0172748, 2017.

[5] The Millennium Development Goals Report, 2011.

[6] P. Release, The Millennium Development Goals Report, 2010.

[7] N. A. van Hest, R. W. Aldridge, G. de Vries et al., "Tuberculosis control in big cities and urban risk groups in the European Union: a consensus statement," Eurosurveillance, vol. 19, no. 9, 2014.

[8] J. Volmink and P. Garner, "Directly observed therapy for treating tuberculosis," Cochrane Library, 2007.

[9] T. R. Frieden and J. A. Sbarbarob, "Promoting adherence to treatment for tuberculosis: the importance of direct observation," Bulletin of the World Health Organization, vol. 85, no. 5, pp. 407-409, 2007.

[10] P. Kardas, P. Lewek, and M. Matyjaszczyk, "Determinants of patient adherence: a review of systematic reviews," Frontiers in Pharmacology, vol. 4, Article ID Article 91, 2013.

[11] P. Kulkarni, S. Akarte, R. Mankeshwar, J. Bhawalkar, A. Banerjee, and A. Kulkarni, "Non-adherence of new pulmonary tuberculosis patients to anti-tuberculosis treatment," Annals of Medical and Health Sciences Research, vol. 3, no. 1, p. 67, 2013.

[12] G. Tesfahuneygn, G. Medhin, and M. Legesse, "Adherence to Anti-tuberculosis treatment and treatment outcomes among tuberculosis patients in Alamata District, northeast Ethiopia," BMC Research Notes, vol. 8, no. 1, article no. 503, 2015.

[13] W. Xu, W. Lu, Y.Zhou, L. Zhu, H. Shen, and J. Wang, "Adherence to anti-tuberculosis treatment among pulmonary tuberculosis patients: a qualitative and quantitative study," BMC Health Services Research, vol. 9, article 169, 2009.

[14] X. Kurhasani, H. Hafizi, E. Toci, and G. Burazeri, "Tuberculosis incidence and case notification rates in kosovo and the balkans in 2012: cross-country comparison," Materia Socio Medica Journal, vol. 26, no. 1, p. 55, 2014.

[15] Kosovo Agency of Statistics, Population and Housing Census 2011, Final Results, People on the Move, Prishtina/Pristina: KAS, 2012.

[16] J. Veen, E. Borroni, L. Gillini, and R. Mehmeti, "Review of the Tuberculosis Programme in Kosovo," United Nations Security Council Resolution 1244, 1999.

[17] W. D. Cuneo and D. E. Snider, "Enhancing patient compliance with tuberculosis therapy," Clinics in Chest Medicine, vol. 10, no. 3, pp. 375-380, 1989.

[18] C. Payne, P. J. Wiffen, and S. Martin, "Interventions for fatigue and weight loss in adults with advanced progressive illness," Cochrane Database of Systematic Reviews, vol. 1, Article ID CD008427, 2012.

[19] A. Mkopi, N. Range, F. Lwilla et al., "Adherence to tuberculosis therapy among patients receiving home-based directly observed treatment: evidence from the united republic of tanzania," PLoS ONE, vol. 7, no. 12, Article ID e51828, 2012.

[20] F. Nuwaha, "High compliance in an ambulatory tuberculosis treatment programme in a rural community of Uganda," International Journal of Tuberculosis and Lung Disease, vol. 3, no. 1, pp. 79-81, 1999. 
[21] R. Heshmat, K. Mohammad, M. R. Mohajeri Tehrani et al., "Assessment of adherence to tuberculosis drug regimen," DARU Journal of Pharmaceutical Sciences, vol. 16, no. 1, pp. 47-50, 2008.

[22] A. Kebede and N. T. Wabe, "Medication adherence and its determinants among patients on concomitant tuberculosis and antiretroviral therapy in south west Ethiopia," North American Journal of Medical Sciences, vol. 4, no. 2, pp. 67-71, 2012.

[23] P. Sardar, A. Jha, D. Roy, S. Roy, P. Guha, and D. Bandyopadhyay, "Intensive phase non-compliance to anti tubercular treatment in patients with HIV-TB coinfection: a hospital-based crosssectional study," Journal of Community Health, vol. 35, no. 5, pp. 471-478, 2010.

[24] V. K. Diwan and A. Thorson, "Sex, gender, and tuberculosis," The Lancet, vol. 353, no. 9157, pp. 1000-1001, 1999.

[25] A. S. Rhines, "The role of sex differences in the prevalence and transmission of tuberculosis," Tuberculosis, vol. 93, no. 1, pp. 104-107, 2013.

[26] G. de Vries, N. A. H. van Hest, H. W. M. Baars, M. M. G. G. Sebek, and J. H. Richardus, "Factors associated with the high tuberculosis case rate in an urban area," The International Journal of Tuberculosis and Lung Disease, vol. 14, no. 7, pp. 859$865,2010$.

[27] A. C. Hayward, T. Darton, J. N. Van-Tam, J. M. Watson, R. Coker, and V. Schwoebel, "Epidemiology and control of tuberculosis in Western European cities," International Journal of Tuberculosis and Lung Disease, vol. 7, no. 8, pp. 751-757, 2003.

[28] G. Fagundez, H. Perez-Freixo, J. Eyene et al., "Treatment adherence of tuberculosis patients attending two reference units in Equatorial Guinea," PLoS ONE, vol. 11, no. 9, Article ID e0161995, 2016.

[29] H. Choi, H. Chung, C. Muntaner et al., "The impact of social conditions on patient adherence to pulmonary tuberculosis treatment," The International Journal of Tuberculosis and Lung Disease, vol. 20, no. 7, pp. 948-954, 2016.

[30] B. Tekle, D. H. Mariam, and A. Ali, "Defaulting from DOTS and its determinants in three districts of Arsi Zone in Ethiopia," The International Journal of Tuberculosis and Lung Disease, vol. 6, no. 7, pp. 573-579, 2002.

[31] E. Hasker et al., "Why do tuberculosis patients default in tashkent city, uzbekistan? a qualitative study," The International Journal of Tuberculosis and Lung Disease, vol. 14, no. 9, pp. 1132$1139,2010$.

[32] E. A. Dodor and G. Y. Afenyadu, "Factors associated with tuberculosis treatment default and completion at the EffiaNkwanta Regional Hospital in Ghana," Transactions of the Royal Society of Tropical Medicine and Hygiene, vol. 99, no. 11, pp. 827832, 2005.

[33] M. K. Gebremariam, G. A. Bjune, and J. C. Frich, "Barriers and facilitators of adherence to TB treatment in patients on concomitant TB and HIV treatment: a qualitative study," BMC Public Health, vol. 10, article 651, 2010.

[34] WHO, Tuberculosis (TB), 2017. 


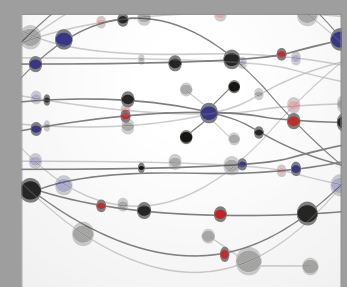

The Scientific World Journal
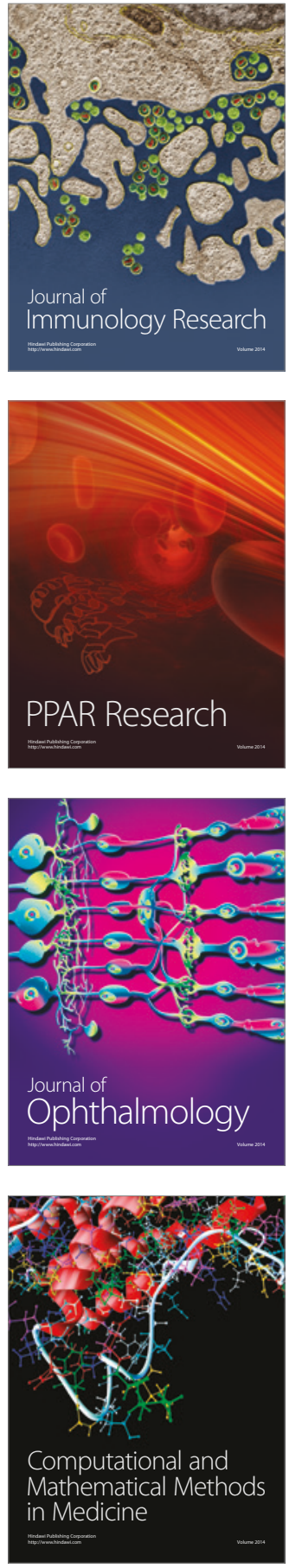

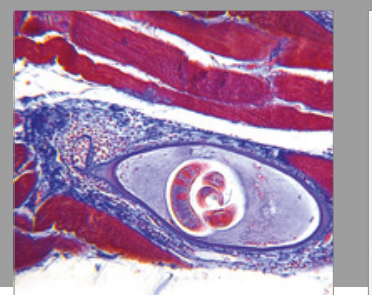

Gastroenterology Research and Practice
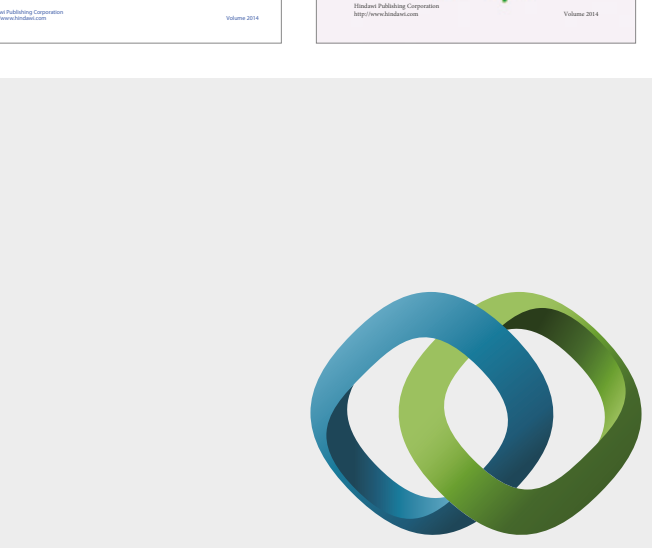

\section{Hindawi}

Submit your manuscripts at

https://www.hindawi.com
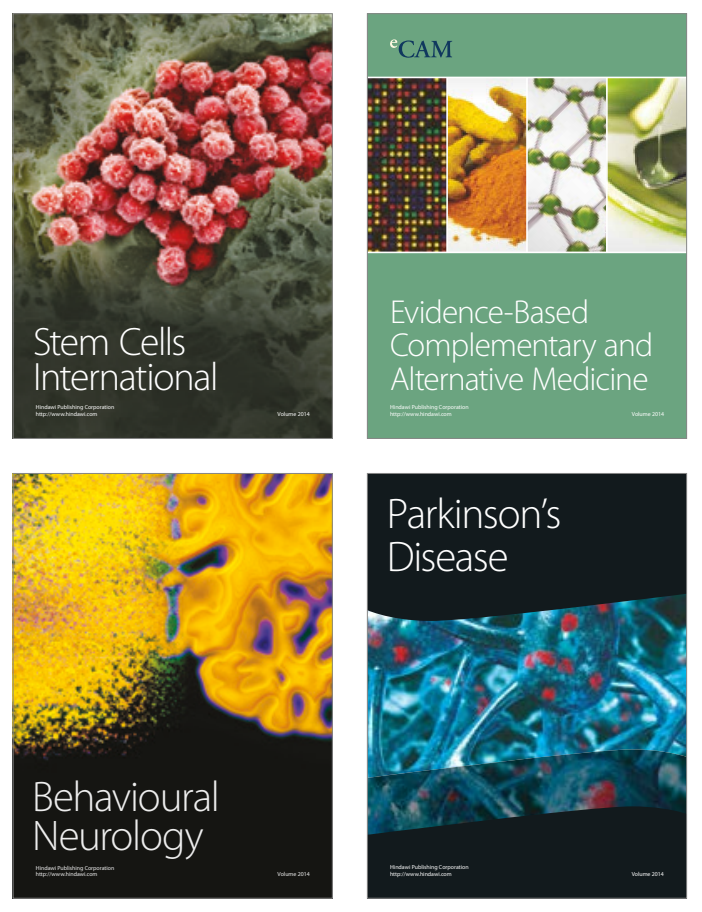
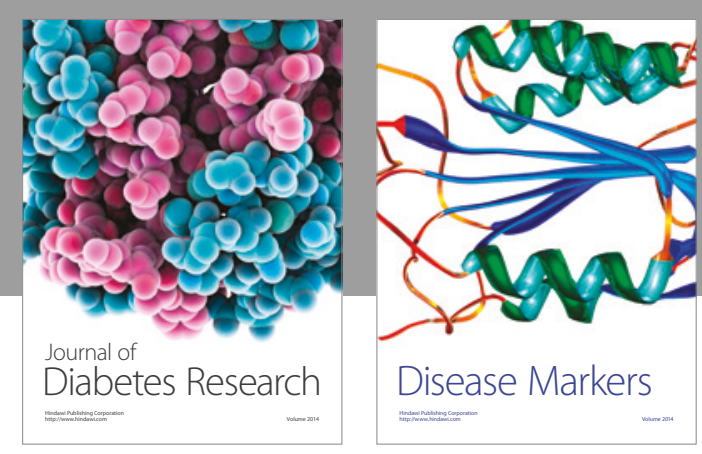

Disease Markers
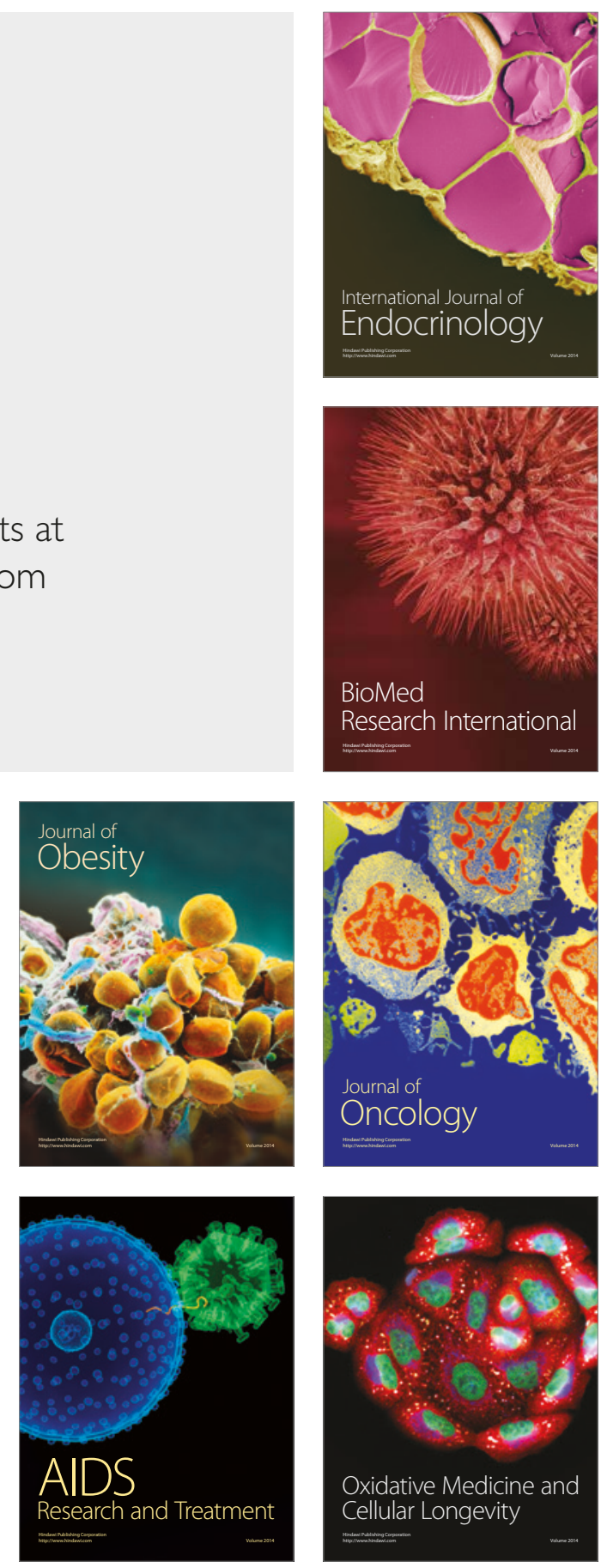